\title{
Measuring absorption of superabsorbent polymers in cementitious environments
}

\author{
Zhao, Shengying; Jensen, Ole Mejlhede; Hasholt, Marianne Tange
}

Published in:

Materials and Structures

Link to article, DOI:

$10.1617 / \mathrm{s} 11527-020-1442-\mathrm{x}$

Publication date:

2020

Document Version

Peer reviewed version

Link back to DTU Orbit

Citation (APA):

Zhao, S., Jensen, O. M., \& Hasholt, M. T. (2020). Measuring absorption of superabsorbent polymers in cementitious environments. Materials and Structures, 53(1). https://doi.org/10.1617/s11527-020-1442-x

\section{General rights}

Copyright and moral rights for the publications made accessible in the public portal are retained by the authors and/or other copyright owners and it is a condition of accessing publications that users recognise and abide by the legal requirements associated with these rights.

- Users may download and print one copy of any publication from the public portal for the purpose of private study or research.

- You may not further distribute the material or use it for any profit-making activity or commercial gain

- You may freely distribute the URL identifying the publication in the public portal

If you believe that this document breaches copyright please contact us providing details, and we will remove access to the work immediately and investigate your claim. 


\title{
Measuring absorption of superabsorbent polymers in cementitious environments
}

\author{
Shengying Zhao ${ }^{\mathrm{ab}}$, Ole Mejlhede Jensen ${ }^{\mathrm{a}}$, Marianne Tange Hasholt ${ }^{\mathrm{a}}$ \\ ${ }^{a}$ Department of Civil Engineering, Technical University of Denmark, Kgs. Lyngby, Denmark \\ $5{ }^{b}$ School of Civil Engineering, Harbin Institute of Technology, Harbin, China
}

Corresponding Author: Shengying Zhao

Phone: +45 5264 4313; +8618845788 058

Fax: +4545883282

10 Email:16B933033@stu.hit.edu.cn

\begin{abstract}
Prior to implementing superabsorbent polymer (SAP) in cement-based materials, the absorption capacity in this environment needs to be known. Two simple methods, the tea-bag method and the filtration method, are often used to measure the SAP absorption capacity in liquid environments. Typically, the two 15 methods give results that do not agree. The scope of this work is to explain the discrepancy between results from the two methods and to examine how well the methods predict the SAP absorption capacity in concrete. The teabag method is modified with different convection conditions during the test, and with various water/cement ratios and hydration times during preparation of cement slurry filtrate that is used as test liquid. The filtration method is modified with different liquid/SAP ratios. Air void analyses of cement paste and concrete are used to 20 assess the SAP absorption capacity in hardened samples. The results reveal that a decrease in absorption capacity observed with the tea-bag method is due to properties of the test liquid and ion exchange between SAP and test liquid. The difference in 24-hour absorption capacities given by the two simple methods is likely due to unequal amounts of interstitial water. It is advised not to use these simple methods as means of estimating SAP absorption capacity in concrete, since the results from these methods do not properly represent the absorption

25 behavior in concrete. Instead, air void analysis of hardened cement paste seems to be a reliable method to register the SAP absorption capacity in cement-based materials.
\end{abstract}

Keywords Superabsorbent polymers, absorption capacity, tea-bag method, filtration method 
Two decades ago, water entrainment by superabsorbent polymer (SAP) particles was reported to be a means of mitigating self-desiccation in cementitious materials, and it was suggested that this additive might be useful for a number of other purposes $[1,2]$. Since then, numerous

5 confirmative studies have been published, and attention has been given to the application of SAP as an additive in a broad context. Such uses include, among others, plastic shrinkage prevention [3], freeze-thaw damage mitigation [4, 5], and self-sealing of cracks [6]. Whatever the reason for implementing SAP into cementitious materials, it is fundamental to know its absorption capacity and ability to release water. Incorrect estimation of this may 10 compromise the properties of cementitious materials (typically concrete) [7, 8].

Water absorbency is often measured by tests methods where SAP is exposed to an entirely liquid environment [9]. These results may not satisfactorily represent the cementitious systems where SAP in addition to pore solution is surrounded by aggregate particles, cement and other solid components. Furthermore, exposure liquids used in these 15 tests (e.g. cement slurry filtrate) may not properly represent the ionic composition of the pore solution in cement-based materials, including its time-dependent change. Such tests, however, are quick and simple to perform and are used e.g. to predict the development of water retention capacity and to make a quantitative comparison between different types of SAP.

20 The tea-bag method and the filtration method are two examples of this kind and they are both recommended by RILEM for the purpose of determining whether a certain type of SAP is suitable for a cementitious material [10]. When using cement slurry filtrate as test liquid in the tea-bag method, some types of SAP show a development of absorption capacity, where the absorption capacity increases in the first 5-10 minutes after first contact with the test 25 liquid. Thereafter it declines within hours [11-19] by various factors ranging up to fifteen [18], and the absorption capacity does not recover at later testing times (up to $24 \mathrm{~h}$ ). The decline is especially prominent when the tested polymers have a high density of anionic groups $[13,14]$. With the high variation of absorption capacity value depending on measuring time, it is unclear which value should be used to determine the dosage of SAP for e.g.

30 mitigating autogenous shrinkage [15]. However, when using the filtration method, and using the same batch of SAP and identical test liquid as used in the tea-bag method, a decrease in absorption capacity is hardly observed [16]. Furthermore, the long-term absorption capacity 
$(12-24 \mathrm{~h})$ is usually higher when it is measured with the filtration method compared with the tea-bag method. As variables regarding materials in the two methods are carefully controlled, there must be some inherent differences in the two methods. Without identification of the reason for the discrepancy, it is questionable to recommend either of them as test methods.

5 Several reasons have been suggested as causes for the declining absorption capacity observed with the tea-bag method (see Section 3.2), but there seems to be no consensus on it. Furthermore, none of the proposed reasons explains why a similar decrease is not observed with the filtration method.

One objective of this study is to explain the inconsistency in absorption capacity results 10 given by the two simple methods. This is reported in Part I of the paper. In one test series SAP is replaced by non-absorbent glass beads, giving a rough estimate on the amount of interstitial water in either method.

Another objective of this study is to evaluate how well the simple test methods done in liquid can predict the absorption capacity in cement-based materials. This is done by

15 comparing results from Part I with those from Part II where the absorption capacity is measured by air void analyses of hardened cement paste and concrete.

\section{Materials}

\subsection{Solid materials}

The SAP is a covalently crosslinked acrylamide/acrylic acid copolymer. It was produced 20 by suspension polymerization with mainly spherical particles. The SAP was rinsed with ethanol following the procedure described by Laustsen et al. [20] to remove possible surfactant. Prior to each test, the SAP was oven dried at $50{ }^{\circ} \mathrm{C}$ for $24 \mathrm{~h}$ to ensure a welldefined, almost-dry moisture state [21]. At this state, the water content of SAP is $1.3 \%$ by mass, as determined by subsequent vacuum-drying over silica gel. Particles were used in their

25 originally produced size distribution $(0-250 \mu \mathrm{m}$ in diameter), except for measurements presented in section 3.2.1, which were based on a mesh sieved range of 50-75 $\mu \mathrm{m}$ validated by optical microscopy. The density of the dry particles is approximately $1500 \mathrm{~kg} / \mathrm{m}^{3}$.

Dense glass beads (Potters A-glass 1922\#, size range 150-250 $\mu \mathrm{m}$ ) with a density of $2500 \mathrm{~kg} / \mathrm{m}^{3}$ were sieved to the mesh size range $180-250 \mu \mathrm{m}$. This material was used for 30 determining the amount of interstitial water. 
Portland cement (CEM I 52.5 N) from Aalborg Portland was used to prepare cement slurry filtrate, cement paste and concrete. The cement has a density of $3140 \mathrm{~kg} / \mathrm{m}^{3}$, Blaine fineness $420 \mathrm{~m}^{2} / \mathrm{kg}$, and Bogue composition (by mass): $\mathrm{C}_{3} \mathrm{~S}: 63 \%, \mathrm{C}_{2} \mathrm{~S}: 12 \%, \mathrm{C}_{3} \mathrm{~A}: 8 \%$, $\mathrm{C}_{4} \mathrm{AF}: 12 \%, \mathrm{Na}_{2} \mathrm{O}$ eq.: $0.6 \%$.

5 Sea dredged sand in the size range of 0-4 mm was used as fine aggregates (density: 2640 $\mathrm{kg} / \mathrm{m}^{3}$; suitable for exposure class XF4 according to EN 206-1). Two size fractions of crushed granite, 4-8 $\mathrm{mm}$ and 8-16 mm, were used as coarse aggregates (densities: $2710 \mathrm{~kg} / \mathrm{m}^{3}$ and $2720 \mathrm{~kg} / \mathrm{m}^{3}$; both suitable for exposure class XF4 according to EN 206-1). Both fine and coarse aggregates have absorptions less than $1 \%$.

\section{$10 \quad 2.2$ Test liquids}

In its basic form, cement slurry was prepared from cement and deionized water with $w / C=5$, as recommended by [10]. $300 \mathrm{~g}$ cement and $1500 \mathrm{~g}$ deionized water were added to a 2-liter beaker and maintained as a suspension by continuous magnetic stirring at a speed of $300 \mathrm{rpm}$ for 24 hours. After that, the slurry was filtered (Macherey-Nagel filter paper, pore

15 size $4-12 \mu \mathrm{m})$. The produced filtrate was colorless and transparent. During stirring and filtering, both the beaker and the funnel were covered with lids to reduce carbonation and evaporation, and the temperature was kept at $20 \pm 1{ }^{\circ} \mathrm{C}$. The $\mathrm{pH}$ of the produced cement slurry filtrate was measured to be $12.8 \pm 0.1$.

Saturated calcium hydroxide solution was prepared in the following way: an excess 20 amount of $\mathrm{Ca}(\mathrm{OH})_{2}$ (Alfa Aesar, purity $>95 \%$ ) was shaken with deionized water. The liquid was later filtered.

\section{Part I: SAP absorption in test liquid - tea-bag method and filtration method}

\subsection{Methods}

\section{3.1.1 The tea-bag method and its adaptations}

In this study, the reference tea-bag method was carried out according to the RILEM recommendation [10]. Moreover, two modified versions were developed from this basis. The decrease in absorption capacity measured by the tea-bag method is reported to be caused by ionic exchange $[14,22]$. As ionic exchange is related to the bulk fluid motion (i.e. 
convection), it is relevant to study how convection conditions influence absorption capacity changes. All tests were done in a climate room at a temperature of $20 \pm 1^{\circ} \mathrm{C}$. The liquid/SAP mass ratio was 900 .

Reference tea-bag method: A dry tea-bag was weighed $\left(m_{T B 1}\right)$. Then SAP was inserted

5 into the tea-bag. The tea-bag containing SAP (total mass $m_{T B 2}$ ) was put into a beaker containing test liquid. The beaker was immediately covered with a LDPE cling film to reduce carbonation and evaporation. 1, 5, 10, 30, $60 \mathrm{~min}, 3$ and $24 \mathrm{~h}$ after the SAP/liquid contact, the tea-bag with swollen SAP was taken out, gently wiped with a dry gauze, and weighed (mass $\left.m_{\text {TB3 }}\right)$. The mass of liquid $\left(m_{\text {TB0 }}\right)$ that can be absorbed by a tea-bag is determined beforehand.

10 As such, absorption capacity (AC) of SAP was calculated by Eq. 1.

$$
A C=\frac{m_{T B 3}-m_{T B 2}-m_{T B 0}}{m_{T B 2}-m_{T B 1}}
$$

The whole test procedure followed the RILEM recommendation with the following exceptions: (1) Approximately $0.1 \mathrm{~g}$ dry particles was used for each sample because of the relatively small tea-bags available (the recommendation suggests $0.2-0.3 \mathrm{~g}$ ); (2) instead of $15200 \mathrm{ml}$ cement slurry filtrate, approx. $100 \mathrm{ml}$ was used for each sample in order to keep the liquid/SAP ratio in accordance with the RILEM recommendation; (3) one tea-bag was only used for one measurement at a point in time, i.e. it was never put back into the beaker to be used for further measurements; (4) some test series included measurements of absorption capacity at $6 \mathrm{~h}$ and $12 \mathrm{~h}$ after liquid contact, which are not part of the RILEM

20 recommendation.

Dipping method: At certain time intervals, the tea-bag immersed in cement slurry filtrate was lifted with a steel thread attached to it and kept above the liquid for 5 seconds, during which liquid on the surface of the tea-bag would drip into the liquid in the beaker. The teabag was then again submerged into the liquid. The dipping action was repeated every minute 25 during the first 10 minutes after test start, every 5 minutes 10-60 minutes after test start, every 15 minutes $1-3$ hours after test start, and every 30 minutes $3-12$ hours after test start. No dipping was conducted from 12 hours after first contact to exposure liquid until the test was ended. During the whole experiment, a plastic enclosure with a tiny, pierced hole at its top covered the beaker to reduce carbonation and evaporation. Fig. 1 illustrates the set-up.

30 Stirring method: In this method, the test liquid (cement slurry filtrate) was stirred with a magnetic rod at a rotation speed of $250 \mathrm{rpm}$ throughout the experiment. The tea-bag was hung at a height where it was not colliding with the rotating rod beneath it while it was still 
fully submerged in the liquid. Some magnetic stirrers develop heat, and this is a potential problem if the absorption capacity is temperature dependent. About $1 \mathrm{~cm}$ of thermal insulation material was placed between the beaker and the magnetic stirrer to reduce heat transfer. The temperature of the liquid was checked and maintained at $20 \pm 1{ }^{\circ} \mathrm{C}$. The

5 insulation material did not influence the stirring.

Precision of the methods: According to the RILEM recommendation [10], measurements with the tea-bag method should be carried out in triplicate. This was done in a pre-test for the reference tea-bag method, where the absorption was registered at 9 different absorption times ( 1 minute $-24 \mathrm{~h})$, i.e. the experiment comprised 27 tea-bags. The coefficients of variance for 10 the 9 absorption times were in the range 1.5-7.4\% (no systematic differences between early and later measurements, as shown in Fig. 2). Due to the low coefficient of variance, it was decided to carry out tests with the reference tea-bag method, the dipping method, and the stirring method with only one tea-bag for each absorption time. This was a matter of priority as it made it possible to carry out the three measuring series in parallel (same operator, almost 15 simultaneous test start on the same day, etc.), thereby ruling out other uncertainties such as temperature differences between test series.

\subsubsection{The filtration method}

The filtration method followed the RILEM recommendation [10]. Dry SAP (mass $m_{F T 1}$ ) was put into an empty beaker. The beaker was then filled with cement slurry filtrate (approx. $100 \mathrm{~mL}$, exact mass $m_{F T 2}$ ). The beaker was immediately covered with a LDPE cling film to reduce carbonation and evaporation. 1, 5, 10, 30, $60 \mathrm{~min}, 3,6$ and $24 \mathrm{~h}$ after the $\mathrm{SAP} /$ liquid contact the liquid was filtered using pre-wetted filter paper (same filter paper as described in section 2.2). Filtered liquid was $m_{F T 3}$ in mass. The absorption capacity $(A C)$ of SAP was determined by Eq. 2 .

When the liquid/SAP mass ratio is 100 (in accordance to RILEM recommendation [10]), SAP at the bottom layer of the beaker has a hindered access to test liquid, when the SAP particles have settled due to gravity. The hindering effect is assumed to be weakened by a thinner layer of SAP particles. This assumption was examined by reducing the amount of

30 SAP while the volume of test liquid remained constant. In addition to the recommended liquid/SAP mass ratio (100), liquid/SAP mass ratios 300 and 900 were tested. 
Precision of the method: According to the RILEM recommendation [10], measurements should be carried out in triplicate when using the filtration method. This was done in a test series with 9 absorption times ( 1 minute $-24 \mathrm{~h}$ ). The coefficients of variance for the 9 registered absorption capacities were in the range $3.2-10.8 \%$. There is a tendency to larger

5 variance at the earliest and the latest measurements. It takes approx. 10-15 minutes to finish the filtration. During the filtration time, the SAP is still to some extent exposed to liquid, so when the filtration time is significant compared to the absorption time, the measurement becomes uncertain. Despite the uncertainty, it was decided to do measurements with different liquid/SAP ratios without triplication, as this made it possible to perform the measurements in 10 parallel.

\subsubsection{Estimation of amount of interstitial water}

Both the tea-bag method and the filtration method were additionally carried out with glass beads instead of SAP, using deionized water as test liquid. As the glass beads do not absorb water, any mass gain during testing was interpreted as retention of interstitial water.

15 To make the simulation as representative as possible, two parameters are crucial: size and amount of glass beads. For SAP the absorbency changes with time, and so do its diameter and total volume. Therefore, it was impossible to set a certain value of size for glass beads to mimic the behavior of SAP. However, as the goal was to obtain the volume of water relative to swollen SAP volume, it was permissible to assume a certain absorption capacity, and $A C=$

$2025 \mathrm{~g} / \mathrm{g}$ was chosen as a rough estimate (which is in reasonable agreement with the actual absorption capacity shown later). This absorption capacity and a density of dry SAP $\rho_{\text {SAP }}=$ $1500 \mathrm{~kg} / \mathrm{m}^{3}$ correspond to that the diameter of a spherical SAP particle increases by a factor of 3.4 during swelling. Based on this, glass beads in the diameter range of 180-250 $\mu \mathrm{m}$ were used to mimic swollen SAP with a diameter of 50-75 $\mu \mathrm{m}$ in the dry state. As regards the 25 amount of glass beads, it was chosen so that the volume of glass beads corresponded to the volume of swollen SAP. For example in the tea-bag method, where $0.1 \mathrm{~g}$ dry SAP is the usual amount used, $2.5 \mathrm{~cm}^{3}$ glass beads was used to mimic the swollen SAP.

In the tea-bag method, the mass of a tea-bag containing dry glass beads was recorded $\left(m_{T B 2}\right)$ as was done in the reference method, and the tea-bag was submerged in deionized

30 water for $24 \mathrm{~h}$, which according to [23] is sufficient time for water to penetrate into the interstices between the glass beads. The tea-bag was taken out, surface dried with gauze, and 
weighed $\left(m_{\text {TB3 }}\right)$. The difference $\left(m_{\text {TB3 }}-m_{\text {TB2 }}\right)$ consisted of two parts: $(1)$ water absorbed by teabag paper $\left(m_{T B 0}\right)$, and (2) water that occupied the interstices between the glass particles.

Eq. 3 can be used to calculate the relative volume of interstitial water:

$$
\begin{array}{ll}
\alpha_{T B}=\frac{\rho_{g}}{\rho_{w}} \cdot \frac{m_{T B 3}-m_{T B 2}-m_{T B 0}}{m_{T B 2}-m_{T B 1}} \quad \text { Eq. } 3
\end{array}
$$

5 where $\alpha_{T B}$ is the volume of interstitial water relative to the volume of glass beads, $\rho_{g}$ is the density of glass beads, $\rho_{w}$ is the density of water.

Similarly, the filtration method was also used to give the relative volume of interstitial water. Due to the higher density of glass compared to swollen SAP, pouring all the glass beads out of the beaker was difficult. Therefore, a plastic wash bottle was used to rinse the

10 beaker wall and release the glass beads into the funnel. The rinsing water was taken into account as part of $m_{F T 2}$. Interstitial water was estimated by Eq. 4 :

$$
\alpha_{F T}=\frac{\rho_{g}}{\rho_{w}} \cdot \frac{m_{F T 2}-m_{F T 3}}{m_{F T 1}}
$$

where $\alpha_{F T}$ is volume of interstitial water relative to the volume of glass beads, $\rho_{g}$ is the density of glass beads, $\rho_{w}$ is the density of water.

\section{$15 \quad 3.2$ Results and discussion}

The absorption capacity of SAP in cement slurry filtrate is measured with the reference tea-bag method and the filtration method. The results are compared in Fig. 3. From 1 minute up to 30 minutes upon liquid contact, an increase by $25 \%$ is observed with either method despite some fluctuations. From then on, absorption measured by the tea-bag method decreases. At 24 h, only about $60 \%$ of the maximum amount is retained. On the contrary, absorption measured with the filtration method was relatively stable. In the time range of 3$24 \mathrm{~h}$, there is hardly any change in absorption within the accuracy of the method. At $24 \mathrm{~h}$, the absorption measured with the filtration method was approximately $75 \%$ larger than that measured with the reference tea-bag method.

25 Initially, it was examined if the tea-bag material was a cause of the decreasing absorption. This was ruled out by an experiment involving extra tea-bag material in the liquid. Likewise, the mesh size of tea-bags did not seem to be relevant, because the decrease in absorption was observed even when "tea-bags" made of tight laboratory filter paper were used. Some types of SAP may degrade and dissolve in the surrounding liquid [24, 25].

30 However, this does not seem to account for the marked absorption capacity decrease in this 
study, as confirmed by mass change of SAP-containing tea-bags before test start and after post-test drying in a $50{ }^{\circ} \mathrm{C}$ oven until constant mass.

To date, several explanations have been suggested for the noticed decrease in absorptivity with progression of time. Pourjavadi et al. [11], for example, reported

5 precipitation of portlandite in the beaker, which was proposed to be the cause of the drastic change. However, in the present study, there was no observation of precipitation in any of the samples.

Crust formation noticed by a number of researchers involved in the RILEM round-robin test was regarded as a possible barrier for absorption [16]. Contrary to this, findings by Zhu et

10 al. [26] suggested that shell-like incrustation played a role in preventing the SAP from further desorbing liquid. As the crusts reported in these works are not necessarily identical in composition, and the fact that no crust was observed in the present study, it is difficult to conclude whether crusts surrounding SAP particles should impede or promote liquid exchange.

\section{$15 \quad 3.2 .1$ Influence of convection}

Fig 4(a) compares the absorption development of SAP in cement slurry filtrate during different convection conditions. When measuring absorption capacity of SAP with the reference tea-bag method, a noticeable drop in absorption capacity is not observed before 3 hours after test start. By regularly dipping the tea-bags or by stirring the liquid, the decrease

20 is observed much earlier, 1 hour or 30 minutes respectively after test start. Interestingly, despite differences in development history, all three measurement conditions result in approximately the same $24 \mathrm{~h}$ absorption capacity. Apparently neither dipping nor stirring makes a difference on long-term absorption capacity of SAP.

Similar observations are made when saturated $\mathrm{Ca}(\mathrm{OH})_{2}$ solution is used as test liquid, see 25 Fig. 4(b). The difference in absorption between 1 minute and $24 \mathrm{~h}$ is even more pronounced. Again, different versions of tea-bag methods end up in the same $24 \mathrm{~h}$ absorption.

In the literature, the decreasing absorption capacity over time is only observed when multivalent cations are present in the test solution, not if the test solution is pure water or if cations are all monovalent $[11-13,17]$. Previous research using the tea-bag method [14] and

30 the filtration method with slight suction [22] has shown that the absorption capacity loss over time was more pronounced, when the concentration of multivalent cations was higher. However, a high total ionic concentration [14] or a high alkalinity [22] restricted the loss of 
absorption capacity over time. It therefore seems that there is an ionic exchange between multivalent cations present in the test liquid (typically $\mathrm{Ca}^{2+}, \mathrm{Al}^{3+}$ ) and monovalent cations (e.g. $\mathrm{Na}^{+}, \mathrm{K}^{+}$) present in the crosslink structure of anionic SAP. If this is the case, the more intense the ionic exchange, the quicker the desorption of SAP. This explanation fits the

5 observations shown in Fig. 4, i.e. ionic exchange is intensified by increasing the liquid convection and this accelerates the absorbency decrease. The reason for a lack of decrease with the RILEM filtration method is discussed in Section 3.2.2.

It should be noted that the observed maximum and subsequent decrease of absorption capacity is not an artefact of the tea-bag method. Similar behavior of SAP has also been 10 observed, when SAP is mixed in e.g. mortar [27].

\subsubsection{Influence of liquid/SAP ratio}

Fig. 5 shows the development of absorption capacity measured with the filtration method with various liquid/SAP ratios. By increasing liquid/SAP from 100 to 300, the absorption capacity at 1 minute increases by approx. $20 \%$, followed by a steady decrease in the

15 following 9 minutes. This decrease is not seen when the same method is used where liquid/SAP ratio is 100 . When the liquid/SAP ratio was elevated to 900 , the absorption capacity at 1 minute is further increased. Hereafter, the absorption capacity drops even more steeply during the following 9 minutes. Despite the pronounced difference in short-term absorption capacity, the long-term absorption capacity does not seem to be influenced as much by the variance of liquid/SAP ratio, considering the uncertainty of this method.

The influence of the liquid/SAP ratio at the early stages can be explained by the "delayed" access to test liquid. It takes time for test liquid to diffuse into the interstices between SAP particles. When liquid/SAP ratio is higher (e.g. 900), it takes less time for all SAP particles to get access to test liquid, resulting in a higher apparent absorption capacity at 25 an early stage (e.g. $1 \mathrm{~min}$ ). As the delay of access does not affect absorption capacity at later stages, short-term absorption capacity looks higher than long-term absorption capacity when liquid/SAP ratio is 900, while such difference is not visible when liquid/SAP is 100.

Furthermore, when the tea-bag method is used, a consistent decrease in absorption capacity does not take place until 30 minutes after liquid contact. On the contrary, such a 30 decrease is captured much earlier, as soon as 1 minute after liquid contact, when using the filtration method where liquid/SAP is 300 or 900. 
The difference in the commencement of decrease in absorption can be explained by the

fact that filtering takes time and delays weighing of the flask that contains filtered liquid. During the filtering process, SAP is still immersed in liquid, so its absorption can change within this period. For example, a nominal 5-minute absorption measurement may in reality

5 be a 20 -minute absorption measurement due to 15 minutes of filtering. Accordingly, the peak value seems to occur earlier, and if it is in the very beginning, a continuous decrease is seen instead of an increase followed by reduction after the peak.

\subsubsection{Influence of test liquid}

Fig. 6(a) shows the effect of changing the $w / c$ of the cement slurry filtrate on the 10 absorption capacity development of SAP tested with the tea-bag method. While the $w / c$ changes from 2.5 to 10 , the hydration time is constant $(24 \mathrm{~h})$. The effect of various hydration times when preparing the cement slurry filtrate with $w / c=5$ is shown in Fig. 6(b).

It can be seen from Fig. 6 that even an apparently minor modification of the cement slurry filtrate has a significant impact on the test outcome, both in terms of when the decrease

15 of absorption capacity occurs and in terms of the magnitude of the final absorption capacity (24 h). This may not be surprising. The composition of pore solution in concrete, among other things, depends on $w / c$ (see e.g. Lothenbach $[28,29]$ ), so cement slurry filtrate prepared at $w / C=5$ is a poor representation of pore solution in concrete. When the composition of the test liquid strongly influences the test result, the implication is that a test carried out with cement slurry filtrate cannot be expected to properly predict the SAP absorption in fresh concrete. Besides $w / c$, the hydration time of the cement slurry before it is filtered also makes a difference. It is known that the total ionic concentration as well as the concentration of calcium ions in cement pore fluid are both relatively stable during the first 6 hours after mixing, but can change considerably during the following 18 hours [30]. Cement slurries

25 prepared with different hydration times might have such variances in ionic concentration, while the magnitude of such variances might not be the same as it is in concrete pore solution. This may explain why the absolute values of absorption capacity are altered when the hydration time of cement slurry is reduced to $6 \mathrm{~h}$ or less.

As previously mentioned, multivalent cations are regarded as a necessary condition for

30 the decrease in absorption capacity with time. However, not all test liquids containing multivalent cations result in the decrease. For example, artificial pore fluid is another commonly used test liquid prepared by dissolving into water compounds containing elements 
typically present in cement paste pore fluid [31,32]. Based on different types of SAP and different cation concentrations in artificial pore fluid where calcium ions are present, no significant decrease in absorption capacity over time was observed with the tea-bag method by e.g. Tabares Tamayo [33].

5 It is not possible to foresee the absorption capacity of SAP in cementitious environments based on measurements in saturated $\mathrm{Ca}(\mathrm{OH})_{2}$ solution. However, saturated $\mathrm{Ca}(\mathrm{OH})_{2}$ solution as test liquid does have advantages when the aim is quality assurance of a SAP production. For example, it is easier to prepare saturated $\mathrm{Ca}(\mathrm{OH})_{2}$ solution than cement slurry filtrate, and it can still reveal differences between batches. It also makes it more straightforward to

10 compare results from different laboratories, which is not possible if the individual laboratories use cement slurry filtrate based on their local cement types.

\subsubsection{Estimation of interstitial water}

There is a considerable gap between long-term absorption capacities measured by the tea-bag method and the filtration method. The reason for this gap needs to be examined. The

15 volume of interstitial water relative to the volume of glass beads is measured in triplicate $(n=$ 3) according to the methods described in Section 3.1.3, see results in Table 1 and Table 2.

The results indicate that for the tea-bag method, the water in the particle interstices is 0.64 relative to glass bead volume. This agrees well with expectations based on random close packing of unisized spheres [34]. The amount of interstitial water involved in the filtration 20 method is 1.16, i.e. much larger than for the tea-bag method. A possible explanation is that when the glass beads were transferred from the beaker to the filter, they were influenced by capillary forces, so they did not flow freely and therefore they did not attain random close packing. This led to a looser packing and thus more interstitial water. The problem is likely to be worse with swollen SAP particles as the density of swollen SAP is lower than the density

25 of glass, and gravity therefore may not compact the swollen SAP particles as much as glass beads. Potentially, one could apply a slight negative pressure (mild vacuum) [22] to examine this supposition.

If $\alpha_{T B}=0.64$ and $\alpha_{F T}=1.16$ are respectively applied to correct the $24 \mathrm{~h}$ measurements shown in Fig. 3, the apparent absorption capacities is reduced from $18.8 \mathrm{~g} / \mathrm{g}$ to $11.1 \mathrm{~g} / \mathrm{g}$ for

30 the tea-bag method, and from $33.0 \mathrm{~g} / \mathrm{g}$ to $14.7 \mathrm{~g} / \mathrm{g}$ for the filtration method. The difference in amounts of interstitial water in the two methods seems to explain a large part of the 
difference in the long-term absorption capacities measured by the tea-bag method and the filtration method.

The calculated water held in interstices between glass beads is only an estimate of water held in SAP interstices. The measured values for interstitial water concerned relatively

5 unisized spheres, and would have been smaller, if the spheres had presented a broader size range. Potentially, SAP and glass beads may also pack differently due to difference in surface properties. However, the measurements seem reasonable, as $\alpha_{T B}$ is quite close to expectations based on random close packing of unisized spheres, and the correction using $\alpha_{T B}$ and $\alpha_{F T}$ considerably reduces the gap between absorption capacities measured with the two methods.

\section{Part II: SAP absorption in cement paste and concrete}

\subsection{Methods}

\subsubsection{Absorption capacity of SAP in cement paste}

A reference cement paste $(\mathrm{CP}-0)$ with $w / c=0.45$ was made by vacuum mixing cement and deionized water for 3 minutes. A similar cement paste (CP-1) was made except that it

15 contained SAP that was dry-mixed with the cement before water was added. Extra water was added at an amount of 18.8 times the mass of SAP (absorption capacity according to the teabag method, $24 \mathrm{~h}$ measurement). Table 3 shows the compositions of the two cement pastes. The fresh cement paste was filled into $250 \mathrm{ml}$ plastic bottles with care to avoid air bubbles. The bottles were sealed and rotated for $24 \mathrm{~h}$ to prevent bleeding. At the age of 7 days, the 20 specimens were cut lengthwise. For either specimen, a $25 \mathrm{~cm}^{2}$ section was ground with silicon carbide abrasive papers with grit sizes of $75,35,17.5$ and $12.5 \mu \mathrm{m}$ successively and analyzed in optical microscopy by the modified point-count method following ASTM C457 [35]. It is a reliable method with documented accuracy, as confirmed by interlaboratory tests $[36,37]$. The magnification used was $50 \times$. The traverse length was $1730 \mathrm{~mm}$ and the

25 translation distance between stops was $200 \mu \mathrm{m}$.

\subsubsection{Absorption capacity of SAP in concrete}

Four concrete mixes were made. Basic $w / c$ ratio was 0.45 for all mixes. The SAP dosages were $0,0.2 \%, 0.4 \%, 0.8 \%$ relative to cement mass. For the three SAP-containing mixes, extra water was added in an amount of 17.8 times that of SAP mass (based on the 
result from the SAP-containing cement paste, see Section 4.2.1). The concrete mix compositions are given in Table 4.

Solid materials were dry mixed in a free-fall mixer for 2 minutes before adding mixing water. After addition of water, 5 minutes of mixing was done. Immediately after mixing,

5 slump, density and air content of the fresh concrete were measured according to EuroNorms [38-40]. One $\varnothing 150 \times 300 \mathrm{~mm}$ cylindrical specimen was cast for each mix. At the age of 7 days, a $20 \mathrm{~mm}$ disc was saw-cut from the center part of each cylinder. After that a $65 \times 65 \times 20$ $\mathrm{mm}^{3}$ specimen was cut from the center of the disc. The two quadratic surfaces of each specimen were ground and analysed in the same way as previously mentioned for cement 10 paste. An example of a ground section of concrete containing SAP is shown in Fig. 7. The wall effect for aggregate was negligible, since the minimal distance of any point on the test surface to the moulded surface of the cylinder was $2.9 \mathrm{~cm}$, corresponding to $\sim 1.8$ times the diameter of the largest aggregate particles. The translation distance between stops was $2 \mathrm{~mm}$. The total length of traverse and total number of points were $4356 \mathrm{~mm}$ and 2178, where the

15 minimum requirements according to the standard are $2286 \mathrm{~mm}$ and 1350 , respectively.

\subsection{Results and discussion}

\subsubsection{Absorption capacity of SAP in cement paste}

Since no stops were found in air voids in the reference mix, it was assumed that all voids in the mix containing SAP were SAP voids, i.e. voids initially occupied by swollen SAP

20 particles. The absorption capacity was measured to be:

$$
A C=\frac{\rho_{w}\left(V_{c p} \cdot \frac{S_{v}}{S_{t}}-V_{S A P}\right)}{m_{S A P}}=\frac{1.0\left(442.6 \cdot \frac{1080}{8650} 2\right)}{3.0}=17.8 \mathrm{~g} / \mathrm{g} \quad \text { Eq. } 5
$$

where $S_{v}$ is the number of points in voids, and $S_{t}$ is the total number of points. Mix design cement paste volume $V_{c p}$, SAP mass $m_{S A P}$ and SAP volume $V_{S A P}$ are given in Table 3. Fig. 8 shows void content versus SAP content in cement paste (together with results for concrete

25 given in the following section). The slope, $k$, of the dashed line in Fig. 8 linking the two points that correspond to the two mixes is related to absorption capacity through Eq. 6 ( $\rho_{S A P}$ is the dry SAP density):

$$
k=1+\frac{\rho_{S A P}}{\rho_{w}} \cdot A C
$$




\subsubsection{Absorption capacity of SAP in concrete}

The air content in the fresh concrete is, within the accuracy of the test method, on the same level for all concrete mixes, see Table 5. There is no indication of a systematic dependence on the SAP dosage. Table 5 also shows measured slump. It is seen that the slump

5 is reduced when SAP is incorporated, but there is no general trend (i.e. a clear relation between slump and SAP dosage).

Assuming that the amount of entrapped air is identical for all mixes and that the volume of SAP increases proportionally with its dosage, the total void content (sum of entrapped air and SAP voids) should be a linear function of SAP dosage relative to concrete volume. As

10 shown in Fig. 8, the measuring points for concrete can be represented by a solid line with a slope $k$ of 25.8 , equivalent to an absorption capacity of $16.6 \mathrm{~g} / \mathrm{g}$, according to Eq. 6 . Comparing the slopes of lines linking any two points, the largest slope and smallest slope give absorption capacities of $18.5 \mathrm{~g} / \mathrm{g}$ and $12.8 \mathrm{~g} / \mathrm{g}$, respectively.

\subsubsection{Comparison between cement paste and concrete}

The measured absorption capacity is $17.8 \mathrm{~g} / \mathrm{g}$ in cement paste, and $16.6 \mathrm{~g} / \mathrm{g}$ in concrete. Potential reasons for this minor difference may include uncertainty in the measurement method, physical restraint by aggregates or discrepancy in pore liquid composition between cement paste and concrete. More experiments are needed to conclude on this. In any case, judged from images such as Fig. 7, breakdown of SAP by grinding aggregate forces is not a 20 likely cause, as no irregularly shaped voids are observed.

Obviously, for SAP used in concrete, the SAP absorption capacity measured in concrete is the "true" absorption capacity. However, the absorption capacities measured in cement paste and in concrete are apparently close. If similar absorption capacities are measured in both materials, then it is advantageous to register the value in cement paste samples:

-It is less time- and resource consuming to mix and cast cement paste.

- It is easier to prepare good quality plane sections of paste specimens; it is more challenging with concrete specimens, especially if the hardness of cement paste and aggregates are very different.

- In the specimens made from cement paste, $100 \%$ of the volume is cement paste and SAP.

30 In our study, the content of paste (including SAP) in the concrete was approx. $40 \%$, i.e. considerably less, and for industrially produced concrete, the paste content is typically even lower. This means that the test area of the plane section needs to be approx. 3 times larger when 
analyzing concrete instead of cement paste to obtain the same accuracy.

- Entrapped air in cement paste can be avoided by vacuum during preparation of the mix, simplifying the SAP void identification and thereby increasing result precision. Vacuum mixing is normally not possible in industrial production of concrete. Also because of entrapment of air

5 during mixing, transportation and placement, measurements of absorption capacity in concrete is more uncertain than similar measurements for paste.

\section{Implication from Part I and Part II}

The $24 \mathrm{~h}$ absorption capacity measured with the tea-bag method $(18.8 \mathrm{~g} / \mathrm{g})$ is relatively close to the absorption capacity measured in concrete $(16.6 \mathrm{~g} / \mathrm{g})$. However, as demonstrated

10 in Section 3.3.4, the absorption capacity measured with the tea-bag method includes a large amount of interstitial water. With interstitial water taken into account, the absorption capacity measured by the tea-bag method $(11.1 \mathrm{~g} / \mathrm{g})$ is significantly lower than what is measured in concrete. It is a complete coincidence that the interstitial water involved in the tea-bag method is compensated by factors such as differences in ionic strength and composition of

15 pore solution and cement slurry filtrate, earlier setting of the concrete than $24 \mathrm{~h}$, etc. Therefore, even though the present study apparently shows partly agreement between measured $24 \mathrm{~h}$ absorption capacity with the tea-bag method and air void analysis of hardened concrete, this will definitely not be the case in general. As regards the filtration method, there are the same reservations as for the tea-bag method with respect to that the test liquid does

20 not reflect the conditions for absorption in concrete. SAP absorption capacity, measured either with the tea-bag method, or the filtration method, is highly time dependent. There is no basis for taking the $24 \mathrm{~h}$ measurement as a prediction of absorption capacity in cement paste, a system which typically takes much less than $24 \mathrm{~h}$ to set. Accordingly, neither the tea-bag method nor the filtration method can be recommended as methods to estimate SAP

25 absorption capacity for mix design of mortar or concrete. In contrast, the absorption capacity can apparently be reliably measured by point counting in a sample of hardened cement paste. This technique, which is well-proven for air void analysis, better reflects the authentic state in concrete. It is a disadvantage that the result is not ready until days after the concrete is placed, so air void analysis is not useful for routine production control, where acceptance or rejection

30 has to be decided before placement. However, the tea-bag method and the filtration method are not useful in any case. The air void analysis can be used for pre-testing, when introducing 
new mix designs, just as it is used for pre-testing in relation to frost resistance, and it can be used for production control of SAP.

Even for determining the suitability of a certain SAP product to be implemented in cement paste or concrete, the tea-bag and filtration methods seem to be problematic. As seen

5 from the results, the sorption kinetics of SAP in a test liquid can be significantly altered due to a single variance of e.g. $w / c$ of cement slurry filtrate. As there are even more differences in properties between test liquid and concrete pore fluid, measuring SAP sorption kinetics in test liquid can hardly be a trustworthy indication of whether a type of SAP is appropriate for use in cement-based materials. Despite appearing to be simple and transparent, the tea-bag

10 method is in reality a complex and misleading technique. However, the tea-bag method might be useful for qualitative assessments of the absorption behavior of SAP, e.g. for production control of SAP to register changes from one batch to another. The filtration method is more misleading than the tea-bag method, especially at exposure times up to $1 \mathrm{~h}$, because the SAP is still in contact with test liquid during the 10-15 minutes it takes to filter a sample.

15 Additionally, more than half of the retained water may be interstitial water - even more than what is found in the tea-bag method.

All experiments and results in this work are based on SAP from suspension polymerization and with a certain chemical composition. Obviously, the results of absorption measurement in liquid will depend on SAP type. However, the dominant problem that renders the quick methods inappropriate is the difference in conditions given by a test liquid and that of a true pore solution inside a concrete ( $w / c$ and hydration time, convection, etc.).

The practical implication of the study is that neither the tea-bag method nor the filtration method can be recommended as a standard test method to assess the absorption capacity of SAP to be used in concrete.

\section{6. Conclusions}

This study investigates two simple test methods to register SAP absorption capacity, i.e. the tea-bag method and the filtration method, and makes a comparison between results obtained by these two methods and results from air void analyses on cement paste and concrete.

30 (a) The tea-bag method initially showed an increase followed by a marked decrease in absorption capacity. The marked decrease in absorption capacity was not observed with the 
filtration method, where absorption capacity was relatively constant in the interval 1 minute to $24 \mathrm{~h}$.

(b) At $24 \mathrm{~h}$ the absorption capacity registered with the filtration method was $75 \%$ higher than the absorption capacity registered by the tea-bag method.

5 The primary cause of the absorption decrease registered by the tea-bag method (a) seemed to be ionic exchange, where multivalent cations from the test solution substitutes monovalent cations in the SAP crosslink structure. Crust formation, portlandite precipitation, or degradation as suggested in the literature were unlikely to be the cause of the absorption decrease in the present study. The conditions for ionic exchange could be modified by 10 changing the convection of the test liquid or by changing the test liquid (e.g. cement slurry filtrate based on different $w / c$ ratios). Such ionic exchange should also be present for the filtration method, but the absorption decrease is not prominent, perhaps because the earlystage absorption is underestimated due to a delay of access to test liquid for the SAP.

The measured absorption capacities by the tea-bag method as well as the filtration 15 method were highly influenced by interstitial water, which does not reflect the absorption in cement-based materials. In the present study, higher amounts of interstitial water were involved in the filtration method compared to the tea-bag method. This can to a high extent explain the difference in long-term absorbency $(b)$.

Neither the tea-bag method nor the filtration method properly predicts the absorption of 20 SAP in a concrete mix, and thus none of them can be recommended as test methods for determining the absorption capacity of SAP in concrete. Contrary to this, air void analyses showed an agreement between the absorption capacities of SAP in cement paste $(17.8 \mathrm{~g} / \mathrm{g})$ and in concrete $(16.6 \mathrm{~g} / \mathrm{g})$. As such, among the methods examined in the present study, only measurement of void structure in hardened cement paste can apparently be used as a reliable 25 alternative to measurement in concrete.

Funding The study was funded by National Natural Science Foundation of China (Grant No. 51778189) and China Scholarship Council (No. 201806120250).

\section{Compliance with ethical standards}

Conflict of Interest The authors declare that they have no conflict of interest. 


\section{Reference}

1. Jensen OM, Hansen PF (2001) Water-entrained cement-based materials: I. Principles and theoretical background. Cem Concr Res 31(4):647-654 https://doi.org/10.1016/S0008-8846(01)00463-X

2. Jensen OM, Hansen PF (2002) Water-entrained cement-based materials: II. Experimental observations. Cem Concr Res 32(6):973-978 https://doi.org/10.1016/S0008-8846(02)00737-8

3. Serpukhov I, Mechtcherine V (2015) Early-age shrinkage of ordinary concrete and a strain-hardening cement-based composite (SHCC) in the conditions of hot weather casting. 10th International Conference on Mechanics and Physics of Creep, Shrinkage, and Durability of Concrete and Concrete Structures. https://doi.org/10.1061/9780784479346.176

4. Hasholt MT, Jensen OM, Laustsen S (2015) Superabsorbent polymers as a means of improving frost resistance of concrete. Advances in Civil Engineering Materials 4(1):237-256 https://doi.org/10.1520/ACEM20150012

5. Mechtcherine V, Schroefl C, Wyrzykowski M, Gorges M, Lura P, Cusson D, Margeson J, De Belie N, Snoeck D, Ichimiya K, Igarashi SI (2017) Effect of superabsorbent polymers (SAP) on the freeze-thaw resistance of concrete: results of a RILEM interlaboratory study. Mater Struct 50(1):14 https://doi.org/10.1617/s11527-016-0868-7

6. Lee HXD, Wong HS, Buenfeld NR (2010) Potential of superabsorbent polymer for self-sealing cracks in concrete. Adv App Ceram 109(5):296-302 https://doi.org/10.1179/174367609X459559

7. Hasholt MT, Jensen OM, Kovler K, Zhutovsky S (2012) Can superabsorent polymers mitigate autogenous shrinkage of internally cured concrete without compromising the strength?. Constr Build Mater 31:226-230 https://doi.org/10.1016/j.conbuildmat.2011.12.062

8. Yang J, Wang F (2019) Influence of assumed absorption capacity of superabsorbent polymers on the microstructure and performance of cement mortars. Constr Build Mater 204:468-478 https://doi.org/10.1016/j.conbuildmat.2019.01.225

9. Schröfl C, Snoeck D, Mechtcherine V (2017) A review of characterisation methods for superabsorbent polymer (SAP) samples to be used in cement-based construction materials: report of the RILEM TC 260RSC. Mater Struct 50(4):197 https://doi.org/10.1617/s11527-017-1060-4

10. Snoeck D, Schröfl C, Mechtcherine V (2018) Recommendation of RILEM TC 260-RSC: testing sorption by superabsorbent polymers (SAP) prior to implementation in cement-based materials. Mater Struct 51(5):116 https://doi.org/10.1617/s11527-018-1242-8

11. Pourjavadi A, Fakoorpoor SM, Hosseini P, Khaloo A (2013) Interactions between superabsorbent polymers and cement-based composites incorporating colloidal silica nanoparticles. Cem Concr Compos 37:196-204

12. Kang SH, Hong SG, Moon J (2017) Absorption kinetics of superabsorbent polymers (SAP) in various cement-based solutions. Cem Concr Res 97:73-83 https://doi.org/10.1016/i.cemconcomp.2012.10.005

13. Schröfl C, Mechtcherine V, Gorges M (2012) Relation between the molecular structure and the efficiency of superabsorbent polymers (SAP) as concrete admixture to mitigate autogenous shrinkage. Cem Concr Res 42(6):865-873 https://doi.org/10.1016/j.cemconres.2012.03.011 
14. Kang SH, Hong SG, Moon J (2018) Importance of monovalent ions on water retention capacity of superabsorbent polymer in cement based solutions. Cem Concr Compos 88:64-72 https://doi.org/10.1016/j.cemconcomp.2018.01.015

15. Wyrzykowski M, Igarashi SI, Lura P, Mechtcherine V (2018) Recommendation of RILEM TC 260-RSC: using superabsorbent polymers (SAP) to mitigate autogenous shrinkage. Mater Struct. 51(5):135 https://doi.org/10.1617/s11527-018-1241-9

16. Mechtcherine V, Snoeck D, Schröfl C, De Belie N, Klemm AJ et al (2018) Testing superabsorbent polymer (SAP) sorption properties prior to implementation in concrete: results of a RILEM Round-Robin Test. Mater Struct 51(1):28 https://doi.org/10.1617/s11527-018-1149-4

17. Farzanian K, Teixeira KP, Rocha IP, Carneiro LD, Ghahremaninezhad A (2016) The mechanical strength, degree of hydration, and electrical resistivity of cement pastes modified with superabsorbent polymers. Constr Build Mater 109:156-165 https://doi.org/10.1016/j.conbuildmat.2015.12.082

18. Schroefl C, Mechtcherine V, Vontobel P, Hovind J, Lehmann E (2015) Sorption kinetics of superabsorbent polymers (SAPs) in fresh Portland cement-based pastes visualized and quantified by neutron radiography and correlated to the progress of cement hydration. Cem Concr Res 75:1-3

https://doi.org/10.1016/j.cemconres.2015.05.001

19. Mechtcherine V, Secrieru E, Schröfl C (2015) Effect of superabsorbent polymers (SAPs) on rheological properties of fresh cement-based mortars-Development of yield stress and plastic viscosity over time. Cem Concr Res 67:52-65 https://doi.org/10.1016/j.cemconres.2014.07.003

20. Laustsen S, Hasholt MT, Jensen OM (2015) Void structure of concrete with superabsorbent polymers and its relation to frost resistance of concrete. Mater Struct 48(1-2):357-368 https://doi.org/10.1617/s11527$\underline{013-0188-0}$

21. Jensen OM (2011) Water absorption of superabsorbent polymers in a cementitious environment. In: Leung CKY, Wan KT (eds) International RILEM conference on advances in construction materials through science and engineering, RILEM Publications S.A.R.L., Hong Kong SAR, pp 22-35

22. Lee HXD, Wong HS, Buenfeld, NR (2018) Effect of alkalinity and calcium concentration of pore solution on the swelling and ionic exchange of superabsorbent polymers in cement paste. Cem Concr Compos 88:150-164 https://doi.org/10.1016/j.cemconcomp.2018.02.005

23. ASTM C29 / C29M - 17a Standard Test Method for Bulk Density (“Unit Weight") and Voids in Aggregate

24. Vandenhaute M, Snoeck D, Vanderleyden E, De Belie N, Van Vlierberghe S, Dubruel P (2017) Stability of Pluronic ${ }^{\circledR}$ F127 bismethacrylate hydrogels: Reality or utopia? Polymer Degradation and Stability 146:201211 https://doi.org/10.1016/j.polymdegradstab.2017.10.003

25. Bouhadir KH, Lee KY, Alsberg E, Damm KL, Anderson KW, Mooney DJ (2001) Degradation of partially oxidized alginate and its potential application for tissue engineering. Biotechnology Progress 17(5):945950 https://doi.org/10.1021/bp010070p

26. Zhu Q, Barney CW, Erk KA (2015) Effect of ionic crosslinking on the swelling and mechanical response of model superabsorbent polymer hydrogels for internally cured concrete. Mater Struct 48(7):2261-2276 https://doi.org/10.1617/s11527-014-0308-5

27. Assmann A (2013) Physical properties of concrete modified with superabsorbent polymers, Dr.-Ing. Thesis, University of Stuttgart 
28. Lothenbach B, Le Saout G, Gallucci E, Scrivener K (2008) Influence of limestone on the hydration of Portland cements. Cem Concr Res 38(6):848-860 https://doi.org/10.1016/j.cemconres.2008.01.002

29. Lothenbach B, Winnefeld F. Thermodynamic modelling of the hydration of Portland cement. Cem Concr Res 36(2):209-226 https://doi.org/10.1016/j.cemconres.2005.03.001

30. Lothenbach B, Winnefeld F, Alder C, Wieland E, Lunk P (2007) Effect of temperature on the pore solution, microstructure and hydration products of Portland cement pastes. Cem Concr Res 37(4):483-491 https://doi.org/10.1016/j.cemconres.2006.11.016

31. Esteves LP (2011) Superabsorbent polymers: On their interaction with water and pore fluid. Cem Concr Compos 33(7):717-724 https://doi.org/10.1016/j.cemconcomp.2011.04.006

32. Aday AN, Osio-Norgaard J, Foster KE, Srubar WV (2018) Carrageenan-based superabsorbent biopolymers mitigate autogenous shrinkage in ordinary portland cement. Mater Struct 51(2):37 https://doi.org/10.1617/s11527-018-1164-5

33. Tabares Tamayo JD (2016) The influence of alkalinity of portland cement on the absorption characteristics of superabsorbent polymers (SAP) for use in internally cured concrete. Master's thesis, Purdue University

34. Scott GD, Kilgour DM (1969) The density of random close packing of spheres. J Phys D-Appl Phys 2(6):863

35. ASTM C 457: "Standard Test Method for Microscopical Determination of Parameters of the Air Void System in Hardened Concrete," American Society for Testing and Materials, West Conshohocken, Pennsylvania, 2000

36. Saucier F, Pleau R, Vézina D (1996) Precision of the air void characteristics measurement by ASTM C 457: results of an interlaboratory test program. Can J Civ Eng 23(5):1118-1128 https://doi.org/10.1139/196-919

37. Elsen J (2001) Automated air void analysis on hardened concrete: Results of a European intercomparison testing program. Cem Concr Res 31(7):1027-1031 https://doi.org/10.1016/S0008-8846(01)00517-8

38. DS/EN 12350-2 (2012) Testing fresh concrete - Part 2: Slump test. Danish Standard

39. DS/EN 12350-6 (2012) Testing fresh concrete - Part 6: Density. Danish Standard

40. DS/EN 12350-7 (2012) Testing fresh concrete - Part 7: Air content - pressure methods. Danish Standard 


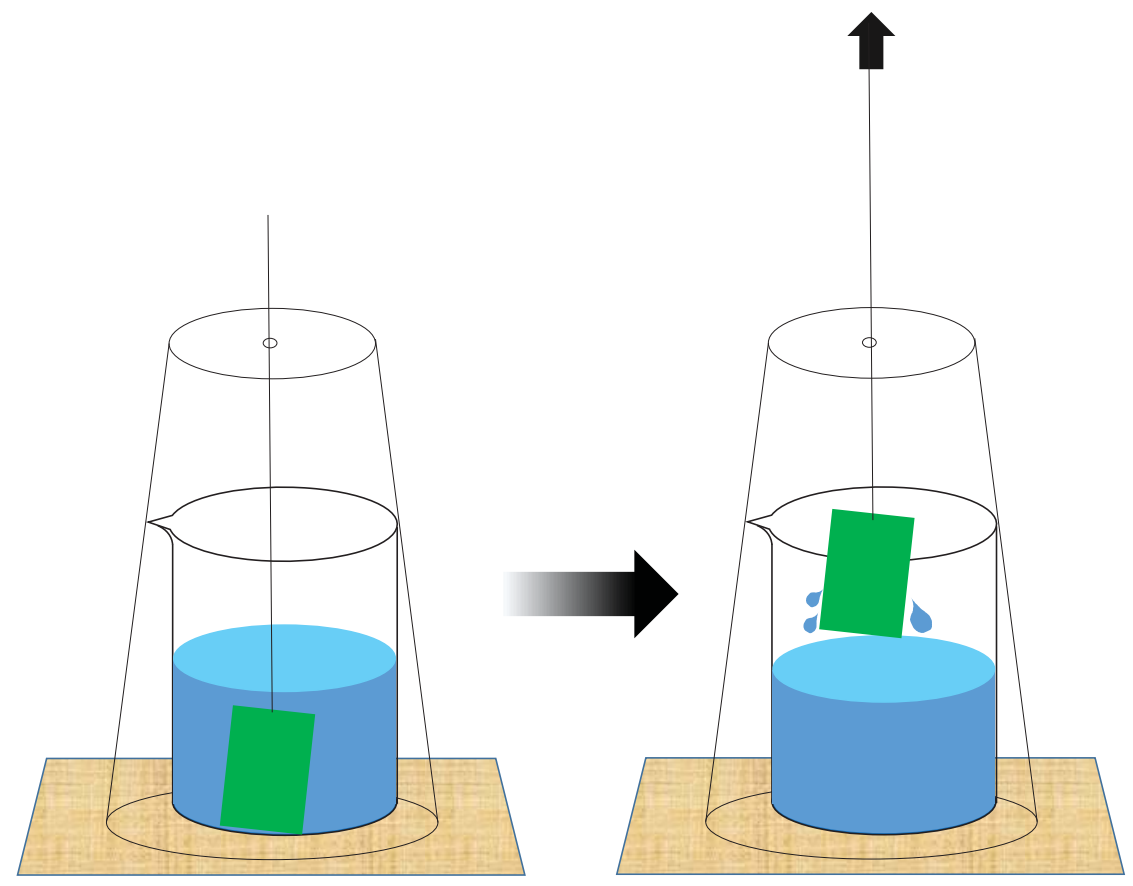

Fig. 1 Sketch of the set-up for the dipping method, a modification of the reference tea-bag method

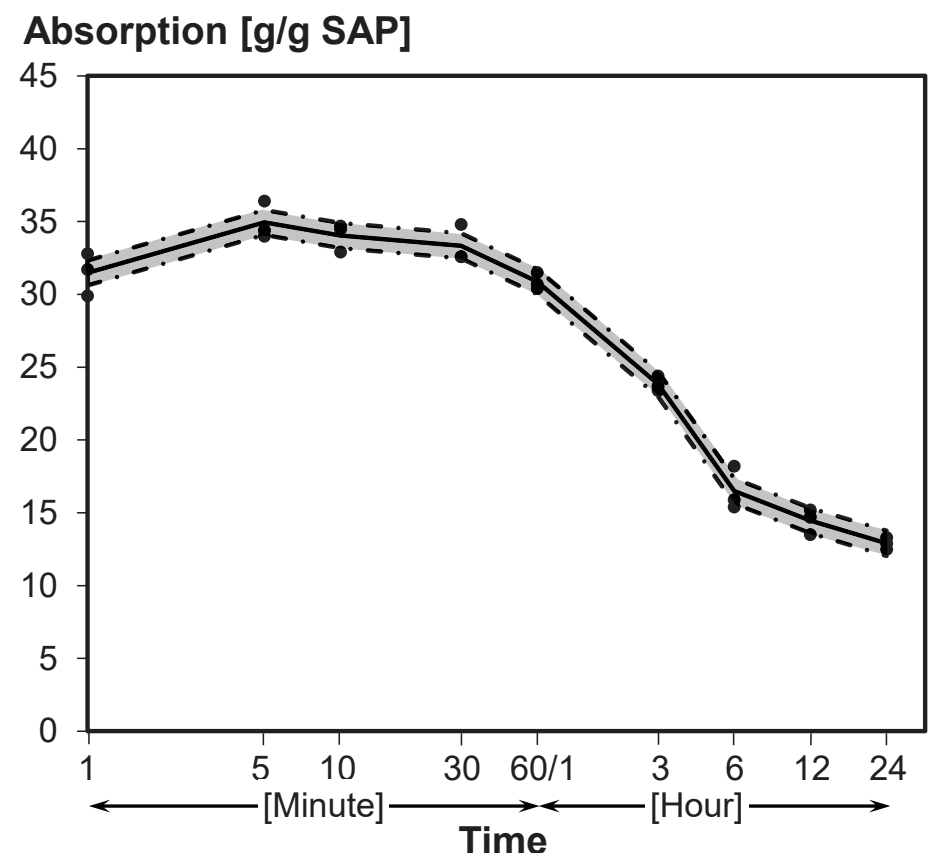

Fig. 2 Development of SAP absorption in saturated $\mathrm{Ca}(\mathrm{OH})_{2}$ solution measured with the tea-bag method in triplicate by the same operator. The solid line denotes the average of absorption measured at each test time. The broken lines indicate the average absolute deviation. The time axis is logarithmic. 


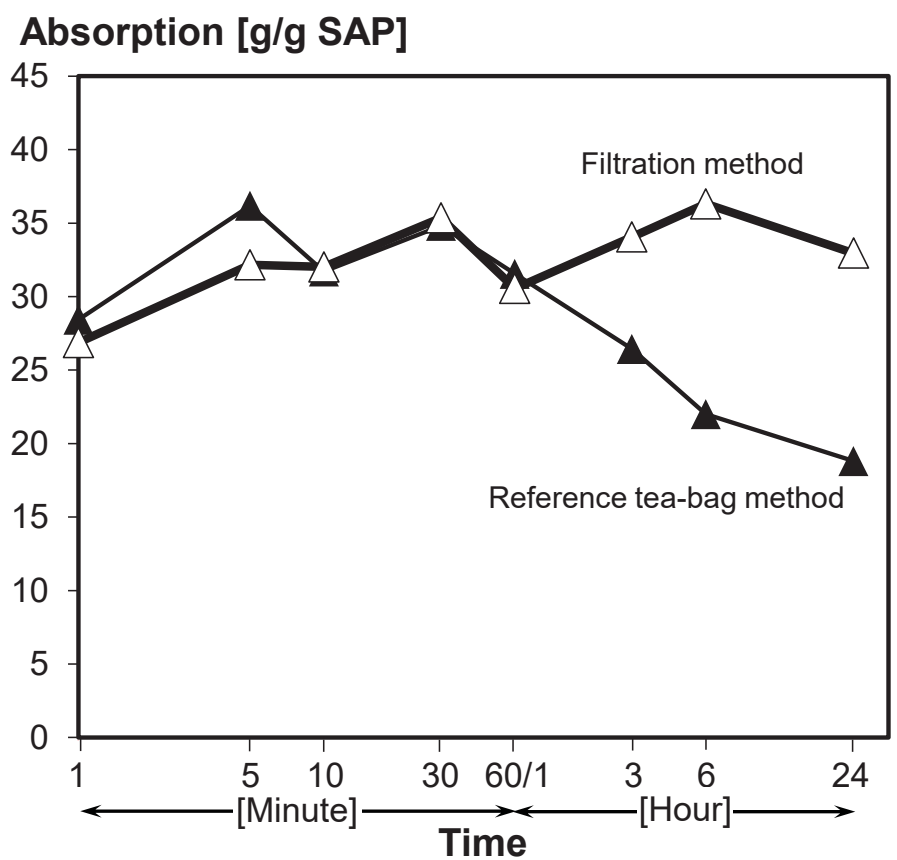

Fig. 3 Development of SAP absorption in cement slurry filtrate, measured with the reference tea-bag method (liquid/SAP=900) and the filtration method (liquid/SAP=100), where liquid/SAP ratios are according to [10]. The time axis is logarithmic. 
(a)

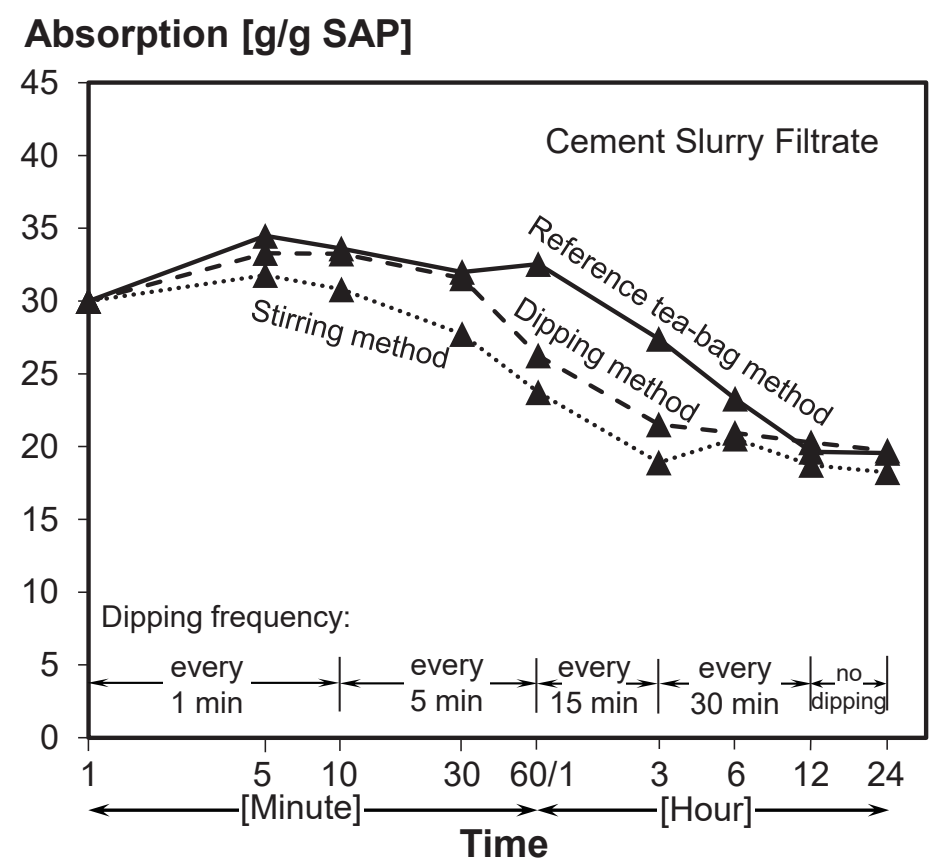

(b)

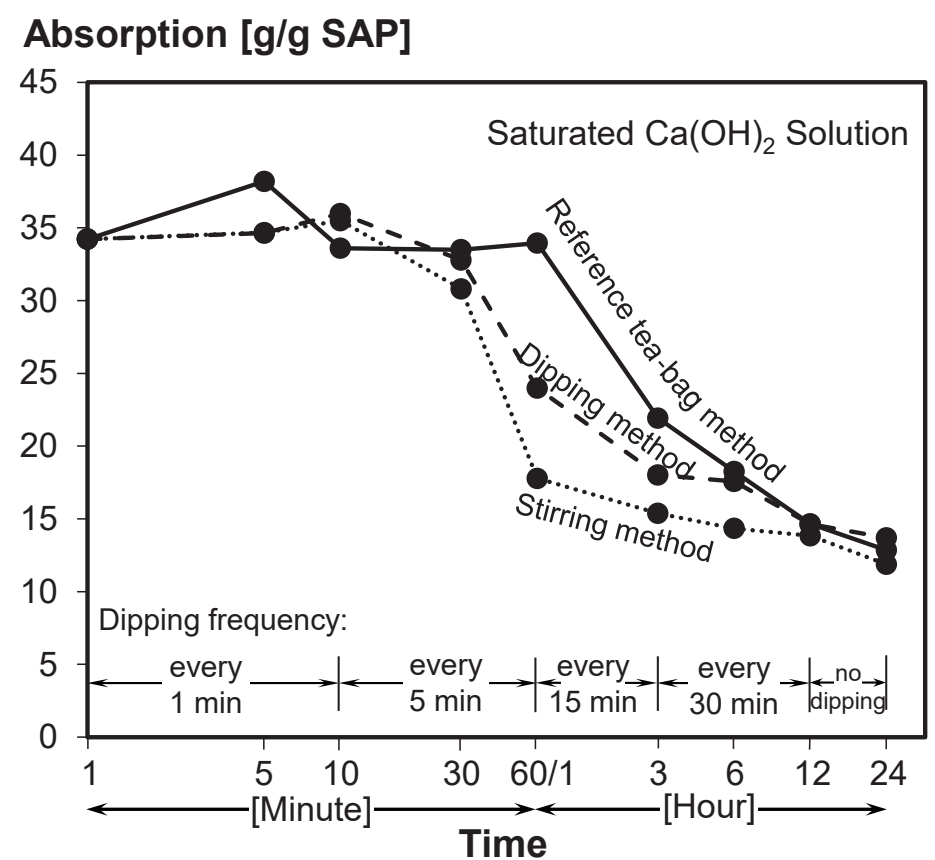

Fig. 4 Absorption development of SAP in (a) cement slurry filtrate and (b) saturated $\mathrm{Ca}(\mathrm{OH})_{2}$ solution. Dipping method and stirring method are used as well as reference tea-bag method. The time axis is logarithmic. 


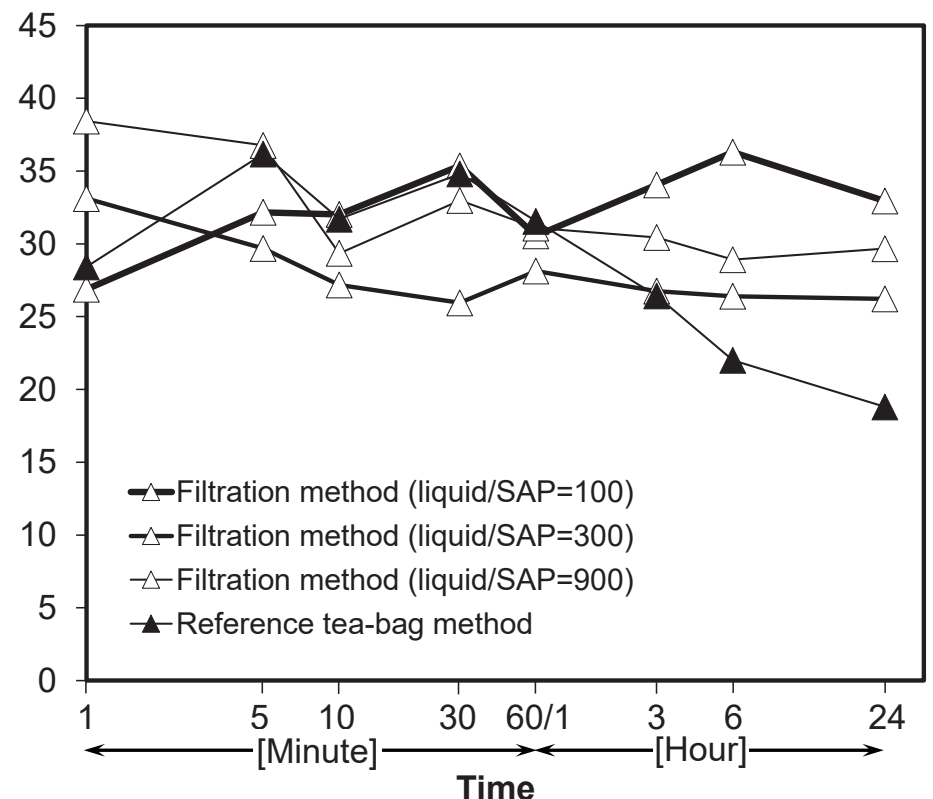

Fig. 5 Absorption development of SAP in cement slurry filtrate, measured with the filtration method where various liquid/SAP ratios are used. Measurements given by the reference tea-bag method are also shown for comparison. The time axis is logarithmic. 
(a)

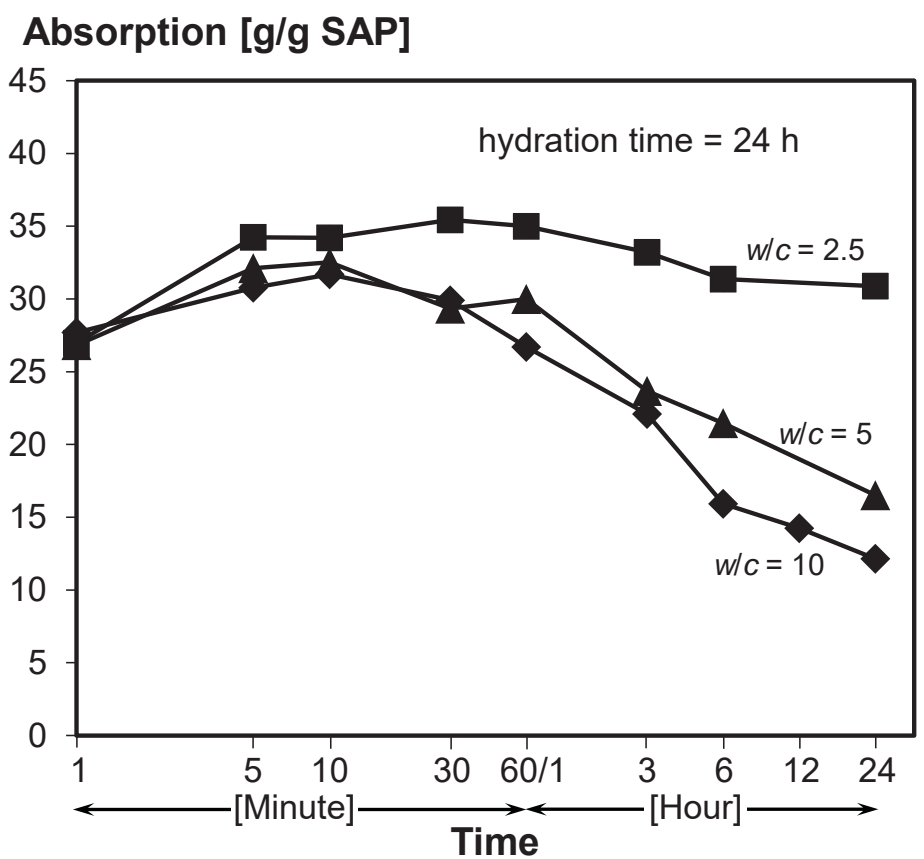

(b)

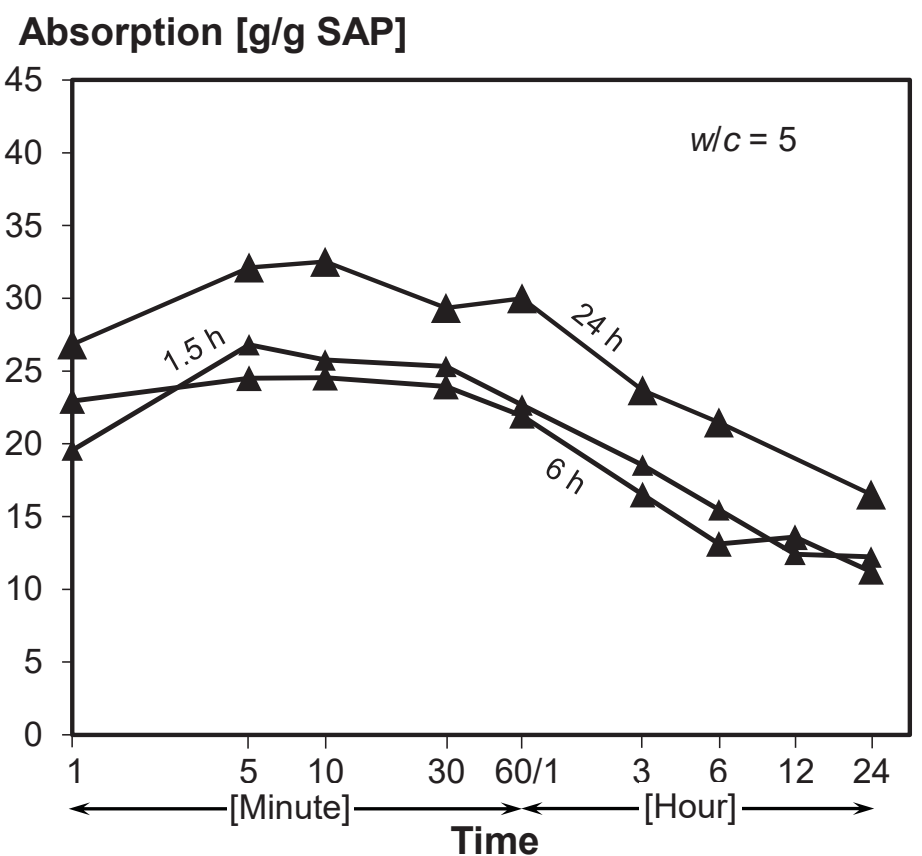

Fig. 6 Effect of modifications of the cement slurry filtrate regarding (a) w/c and (b) hydration time before the slurry is filtered. The tests are carried out with the tea-bag method. The time axis is logarithmic. 
1

2

3

4

5

6

7

8

10

11

12

13

14

15

16

17

18

19

20

21

22

23

24

25

26

27

28

29

30

31

32

33

34

35

36

37

38

39

40

41

42

43

44

45

46

47

48

49

50

51

52

53

54

55

56

57

58

59

60

61

62

63

64

65

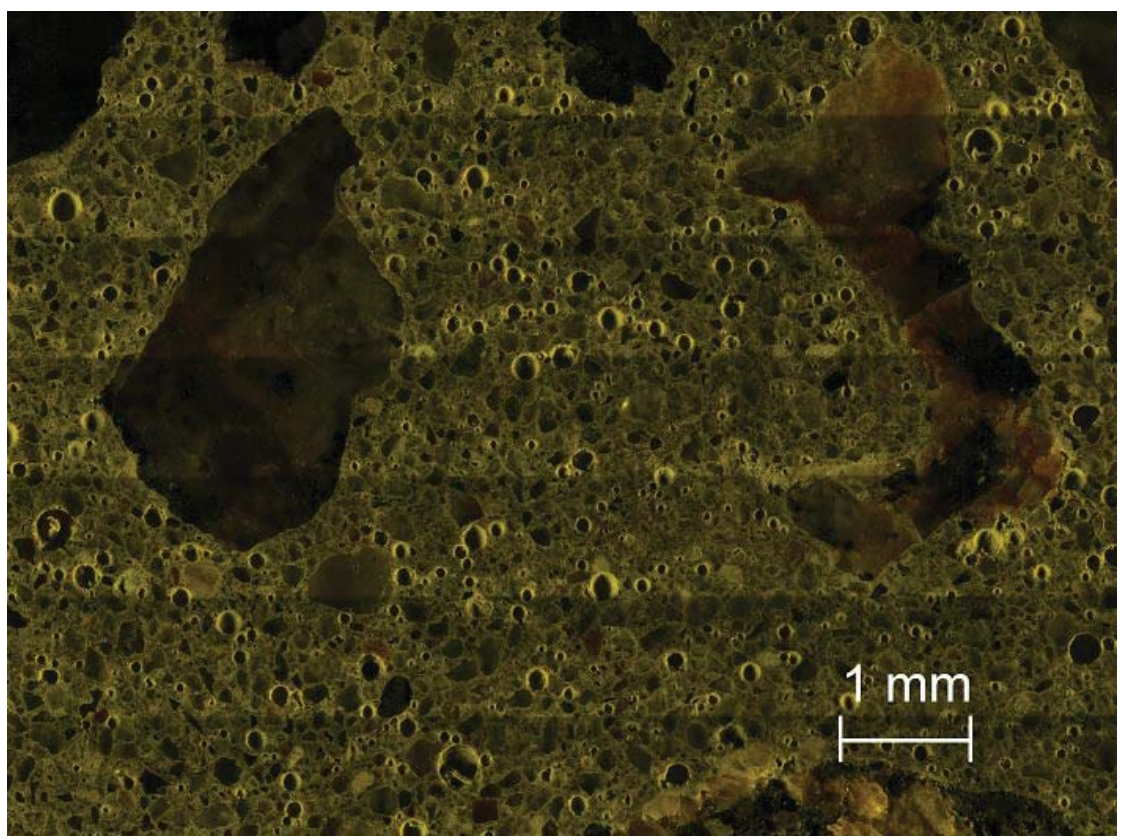

Fig. 7 A ground section of concrete (CO-2) observed by optical microscopy. The image is a merge of 49 images each captured at $50 \times$ magnification.

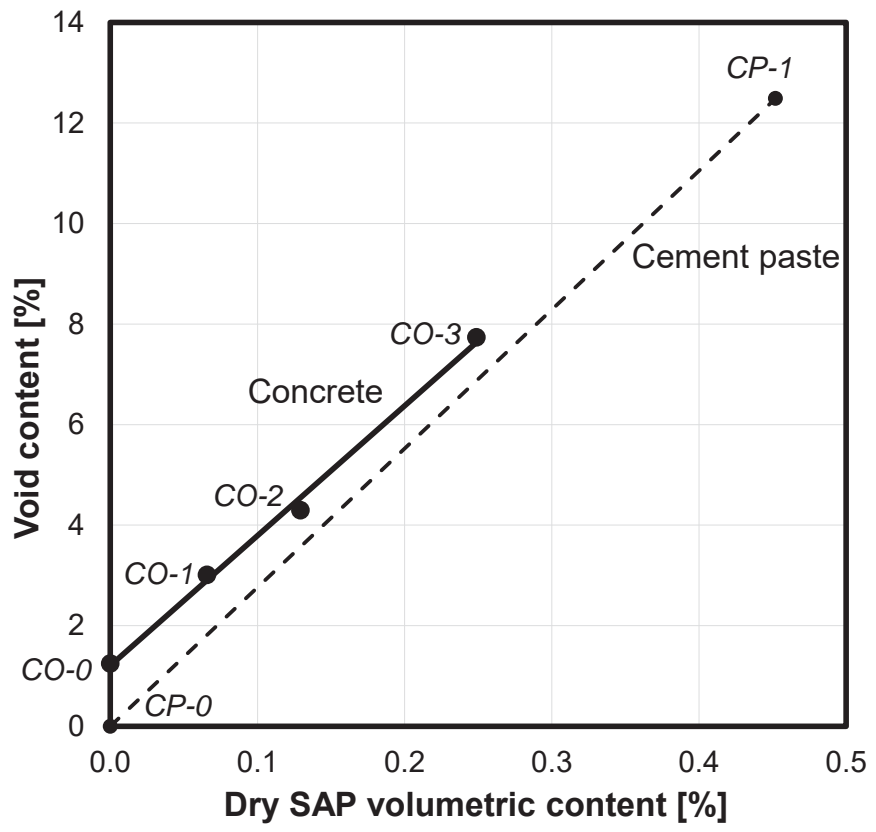

Fig. 8 Relations between void contents and dry SAP volumetric contents in concrete and cement paste 
1

2

3

4

5

6

7

8

9

10

11

12

13

14

15

16

17

18

19

20

21

22

23

24

25

26

27

28

29

30

31

32

33

34

35

36

37

38

39

40

41

42

43

44

45

46

47

48

49

50

51

52

53

54

55

56

57

58

59

60

61

62

63

64

65

Table 1 Measurements of the relative volume of interstitial water captured between glass beads with the tea-bag method. $\alpha_{T B}$ is defined by Eq. 3 .

\begin{tabular}{cccccccc}
\hline Sample No. & $m_{\text {TB0 }}[\mathrm{g}]$ & $m_{\text {TB1 }}[\mathrm{g}]$ & $m_{\text {TB2 }}[\mathrm{g}]$ & $m_{\text {TB3 }}[\mathrm{g}]$ & $\rho_{g}\left[\mathrm{~kg} / \mathrm{m}^{3}\right]$ & $\rho_{w}\left[\mathrm{~kg} / \mathrm{m}^{3}\right]$ & $\alpha_{T B}[-]$ \\
\hline 1 & 0.222 & 0.093 & 6.320 & 8.096 & 2520 & 1000 & 0.63 \\
2 & 0.217 & 0.091 & 6.368 & 8.181 & 2520 & 1000 & 0.64 \\
3 & 0.217 & 0.091 & 6.318 & 8.136 & 2520 & 1000 & 0.65 \\
Mean & & & & & & & 0.64 \\
\hline
\end{tabular}

Table 2 Measurements of the relative volume of interstitial water captured between glass beads with the filtration method. $\alpha_{F T}$ is defined by Eq. 4 .

\begin{tabular}{ccccccc}
\hline Sample No. & $m_{F T 1}[\mathrm{~g}]$ & $m_{F T 2}[\mathrm{~g}]$ & $m_{F T 3}[\mathrm{~g}]$ & $\rho_{g}\left[\mathrm{~kg} / \mathrm{m}^{3}\right]$ & $\rho_{w}\left[\mathrm{~kg} / \mathrm{m}^{3}\right]$ & $\alpha_{F T}[-]$ \\
\hline 1 & 6.230 & 120.716 & 117.844 & 2520 & 1000 & 1.16 \\
2 & 6.258 & 135.528 & 132.839 & 2520 & 1000 & 1.08 \\
3 & 6.252 & 150.307 & 147.247 & 2520 & 1000 & 1.23 \\
Mean & & & & & & 1.16 \\
\hline
\end{tabular}

Table 3 Mix design of cement pastes with SAP (CP-1) and without SAP (CP-0)

\begin{tabular}{lcrrrr}
\hline \multirow{2}{*}{ Constituent } & Density & \multicolumn{2}{c}{ Mass $m[\mathrm{~g}]$} & \multicolumn{2}{c}{ Volume $V\left[\mathrm{~cm}^{3}\right]$} \\
\cline { 3 - 6 } & $\rho\left[\mathrm{g} / \mathrm{cm}^{3}\right]$ & $\mathrm{CP}-0$ & $\mathrm{CP}-1$ & $\mathrm{CP}-0$ & \multicolumn{1}{c}{$\mathrm{CP}-1$} \\
\hline Cement & 3.14 & 500.0 & 500.0 & 159.2 & 159.2 \\
Water & 1.00 & 225.0 & 281.4 & 225.0 & 281.4 \\
SAP & 1.50 & 0.0 & 3.0 & 0.0 & 2.0 \\
Sum, cement paste & - & 725.0 & 784.4 & 384.2 & 442.6 \\
\hline
\end{tabular}

Table 4 Composition of $1 \mathrm{~m}^{3}$ concrete (assuming $0.015 \mathrm{~m}^{3}$ entrapped air) with different dosages of SAP. Densities of aggregates refer to the saturated, surface dry state (SSD). Aggregate and water masses were adjusted for deviations from SSD.

\begin{tabular}{lccccc}
\hline \multirow{2}{*}{ Constituent } & \multirow{2}{*}{ Density $\left[\mathrm{kg} / \mathrm{m}^{3}\right]$} & \multicolumn{4}{c}{ Mass $[\mathrm{kg}]$} \\
\cline { 3 - 6 } & & CO-0 & CO-1 & CO-2 & CO-3 \\
\hline Cement & 3140 & 500 & 491 & 482 & 466 \\
Water & 1000 & 225 & 238 & 251 & 276 \\
Fine agg. & 2640 & 633 & 622 & 611 & 590 \\
Coarse agg. (4-8 mm) & 2710 & 195 & 192 & 188 & 182 \\
Coarse agg. $(8-16 \mathrm{~mm})$ & 2720 & 783 & 769 & 755 & 729 \\
SAP & 1500 & 0.0 & 1.0 & 1.9 & 3.7 \\
Sum & - & 2336 & 2313 & 2289 & 2246 \\
\hline
\end{tabular}

Table 5 Fresh concrete properties

\begin{tabular}{lcccc}
\hline & CO-0 & CO-1 & CO-2 & CO-3 \\
\hline Slump $[\mathrm{mm}]$ & 155 & 65 & 90 & 85 \\
Density $\left[\mathrm{kg} / \mathrm{m}^{3}\right]$ & 2374 & 2347 & 2321 & 2274 \\
Air content $[\%]$ & 1.0 & 1.3 & 1.1 & 1.4 \\
\hline
\end{tabular}

